\title{
NIGHT WORK AND BREAST CANCER RISK AMONG
} NORWEGIAN NURSES

Jenny-Anne Lie, ${ }^{1}$ Helge Kjuus, ${ }^{1}$ Shan Zienolddiny, ${ }^{1}$ Aage Haugen, ${ }^{1}$ Richard Stevens, ${ }^{2}$ Kristina Kjærheim ${ }^{1}{ }^{1} \mathrm{NIOH}$, Oslo, Norway; ${ }^{2}$ University of Connecticut, Farmington, USA; ${ }^{3}$ Cancer Registry of Norway, Oslo, Norway

10.1136/oemed-2011-100382.53

Objectives To examine the relationship of shift work and breast cancer risk by different exposure metrics of night shift work.

Methods A nested case-control study was performed among Norwegian nurses who graduated before 1985. Cases of breast cancer were identified by linking the Norwegian Cancer Registry to the Norwegian Board of Health's registry of nurses. A total of $699(74 \%)$ of the live cases (diagnosed 1990-2007) and 895 (65\%) of the frequency-matched controls, cancer-free at the time of sampling, were interviewed about known and suspected risk factors, including a detailed occupational history. ORs for risk of breast cancer in relation to new and previously used exposure metrics were estimated by multivariate unconditional logistic regression models.

Results No increase of risk was found after long duration with $\geq 3$ night shifts per month. Non-significantly increased risks were observed for $\geq 30$ years in hospitals or other institutions $(\mathrm{OR}=1.1), \geq 12$ years in schedules including night work $(\mathrm{OR}=1.3), \geq 1007$ night shifts during lifetime $(\mathrm{OR}=1.2)$, lifetime average number of night shifts per month $\geq 4(\mathrm{OR}=1.2)$, and $\geq 5$ years with $\geq 4$ and $\geq 5$ consecutive night shifts ( $O R=$ 1.4 to 1.6 ). Significantly increased risk was found for $\geq 5$ years with $\geq 6$ consecutive night shifts ( $O R=1.8,95 \%$ CI 1.1 to 2.8).

Conclusions Breast cancer risk may be related to number of consecutive night shifts. 